\title{
Correction to: High-Voltage Superconducting Fault Current Limiters Based on High-Diffusivity Dielectric Substrates
}

\author{
Guy Deutscher ${ }^{1}$
}

Published online: 16 June 2018

(C) Springer Science+Business Media, LLC, part of Springer Nature 2018

\section{Correction to: J Supercond Nov Magn (2018) 31:1961-1963 https://doi.org/10.1007/s10948-018-4633-8}

The original version of this article contains the following mistakes:

On the second page 1st paragraph under heading "The Role of the Substrate Diffusivity" second and third sentences, $90 \mathrm{~K}$, $300 \mathrm{~cm}^{2} / \mathrm{s}$ and $5 \mathrm{~mm}$, should be replaced with $65 \mathrm{~K}, 100 \mathrm{~cm}^{2} / \mathrm{s}$ and $3 \mathrm{~mm}$, respectively. Still on the same page, under heading "Maximum Power", $0.5 \mathrm{~cm}$ and $15,000 \mathrm{~W} / \mathrm{cm}^{2}$ should be replaced with $0.3 \mathrm{~cm}$ and $9000 \mathrm{~W} / \mathrm{cm}^{2}$, respectively. Corrected sentences should read:

At $65 \mathrm{~K}$, the critical temperature of the HTS layer, its value is about $100 \mathrm{~cm}^{2} / \mathrm{s}$. If a hot spot develops because of the presence of some defect in the HTS layer, within $1 \mathrm{~ms}$, the temperature increase of the substrate is smoothed out over the length scale $\delta=3 \mathrm{~mm}$, which is of the order of a typical tape width.

Taking a value of $1 \mathrm{~J} / \mathrm{cm}^{3}$, and $\delta=0.3 \mathrm{~cm}$, we get a maximum power of $9000 \mathrm{~W} / \mathrm{cm}^{2}$.

Also, on the third page last sentence under heading "Shunt Optimization for Achieving Highest Possible Electric Field", $5 \mathrm{kV} / \mathrm{m}$ should be replaced with $3 \mathrm{kV} / \mathrm{m}$. Corrected sentence should read:

For a critical current of $300 \mathrm{~A} / \mathrm{cm}-\mathrm{w}$, the maximum electric field that can be achieved will be $3 \mathrm{kV} / \mathrm{m}$ for a sapphirebased tape and $130 \mathrm{~V} / \mathrm{m}$ for a Hastelloy-based tape.

The original article has been corrected.
The online version of the original article can be found at https://doi.org/10.1007/s10948-018-4633-8.

Guy Deutscher

guyde@tau.ac.il

1 School of Physics and Astronomy, Tel Aviv University, Ramat Aviv, 69978 Tel Aviv, Israel 